\title{
Amphetamine-Induced Conditioned Place Preference and Modeling Domains of Bipolar Disorder
}

\author{
Shlomit Flaisher-Grinberg ${ }^{+}$and Haim Einat*
}

Department of Pharmacy Practice and Pharmaceutical Sciences, College of Pharmacy, University of Minnesota, USA

\begin{abstract}
The development of appropriate models for bipolar disorder (BPD) is a critical step in the efforts to further study the underlying pathology of the disorder and develop novel treatments. One approach to achieve better models is to develop a battery of tests for the different behavioral domains of the disease. Previous work examined ways to model reward-related behaviors in the context of BPD with some success. Because disregulation of the reward system is one of the hallmarks of BPD the present study was designed to evaluate the possibility of using amphetamine-induced conditioned place preference (CPP) as an additional method to model the reward seeking behavioral domain in BPD.

To evaluate the pharmacological (predictive) validity of amphetamine-induced CPP for BPD, the study examined the effects of the prototypic mood stabilizer lithium in a biased (black/white) amphetamine-induced CPP paradigm. To delineate generalized effects of drugs, animals were also tested for locomotor activity at the end of the CPP paradigm.

As expected, amphetamine pairing resulted in the development of CPP, evidenced by an increase in the time spent in the paired compartment from pre-conditioning to post-conditioning sessions. Lithium had no effects on the expression of CPP or on locomotor activity.

The results suggest that amphetamine-induced CPP lacks pharmacological validity and it is therefore not a good choice as a model for the reward-seeking domain of BPD. Additional tests should be explored as suitable modes for this important component of the disorder.
\end{abstract}

Keywords: Affective disorders, animal models, pleasure seeking, mood stabilizers.

\section{INTRODUCTION}

Bipolar disorder (BPD) is a chronic and debilitating illness which includes alternate episodes of depression and mania [1]. The paucity of appropriate animal models for BPD hinders the research of its pathophysiology and the development of new treatments for this condition $[2,3]$. One of the possible approaches to overcome the challenge of appropriate models is by using separate models for different behavioral domains of the disorder [4-8]. While a single model that will represent the entire scope of BPD might not be attainable at this time, individual models representing domains of the disorder have been developed and offer support for further research. Research using limited but valid models for distinct domains of BPD might shed light on disease mechanisms and the therapeutic mechanisms of action of mood stabilizers leading to the development of better models.

The most frequently used model for a domain of mania is amphetamine-induced hyperactivity (for review see [9]). Recently, other tests were identified and validated and can be

*Address correspondence to this author at the Department of Pharmacy Practice and Pharmaceutical Sciences, College of Pharmacy, Duluth, University of Minnesota, 123 Life Science, 1110 Kirby Dr. Duluth, MN 55812, USA; Tel: 218-726-6029; Fax: 218:726-6500;

E-mail: heinat@d.umn.edu

${ }^{+}$Present Affiliation: Department of Pharmacology, University of Minnesota Medical School, Minneapolis, Minnesota. used to explore additional domains of the disorder [10-14]. One important domain of mania, an increase in reward seeking and a disregulation of the reward system, had been demonstrated at the behavioral, neuroanatomical and neurochemical levels [15-17] and was suggested as a relevant endophenotype of the disease [18]. In some recent works, our laboratory has showed that one possible way to model the reward seeking domain of BPD is by using the sweet solution preference test. Specifically, we showed that sweet solution preference varies across mice strains and that in mice with high baseline preference (modeling high reward seeking), the mood stabilizers lithium and valproate reduce preference while the antidepressant imipramine has no effects $[11,12]$. These previous findings suggest that sweet solution preference can be utilized as part of a battery of tests for the separate domains of the disorder. However, sweet solution preference is limited to animals that have a baseline high preference and its usefulness in strains or species where this preference is lower is not clear. Another interesting attempt to model reward seeking behavior in the context of BPD is the female urine sniffing test [14]. However, this test was validated more in the context of depression and less in the context of mania. Additional ways to evaluate reward seeking behaviors in the context of BPD modeling are therefore of significant value.

One well studied method to test for reward seeking as well as for the rewarding value of compounds is the Conditioned Place Preference paradigm (CPP, for reviews 
see $[19,20])$. Conceptually, the CPP paradigm includes repeated pairing of a specific location with a specific stimulus. When paired stimulus is rewarding to the animal, the preference for the paired location increases. Numerous compounds and substances were evaluated using the CPP paradigm and in a variety of animal strains and species. One group of compounds that were repeatedly demonstrated to induce CPP is psychostimulant drugs including amphetamine [21-23].

Amphetamine treatment and amphetamine-induced behavior have significant importance in the context of BPD because of a number of reasons: (1) Amphetamine-induced hyperactivity is probably the most common manner to induce a manic-like model (for review see [9]); (2) In humans, amphetamine can induce mania in susceptible individuals [24] and (3) clinical studies support the effects of lithium to ameliorate the behavioral effects of stimulants in people $[25,26]$.

The effects of mood stabilizing drugs were previously evaluated in the CPP paradigm but without direct implications to BPD. Specifically, lithium and valproate were shown to attenuate morphine-induced CPP $[27,28]$ but no effects of valproate were demonstrated in diazepam induced CPP [29] and lithium was shown to increase cocaine induced CPP [30].

Because of the need for additional ways to model domains of BPD and the specific relevance of amphetamineinduced behaviors in the context of BPD, the present study was designed to evaluate the effects of the prototypic mood stabilizer lithium on amphetamine-induced CPP. The testing of the effects of lithium is essential to explore possible pharmacological validity of amphetamine-induced CPP in the context of BPD.

\section{MATERIALS AND METHODOLOGY}

\section{Animals}

Black Swiss mice (Taconic, NY, USA) served as subjects. This strain was selected based on previous results in the amphetamine-induced hyperactivity model and the sweet solution preference model (e.g. [12]). All mice were transported to our laboratory, where experimentation started no less than 1 week later to allow for appropriate acclimatization time. Male mice, 10 to 12 weeks old and 25 $\pm 5 \mathrm{~g}$ at the start of treatment period, were singly housed in a colony room with constant temperature $\left(22 \pm 1^{\circ} \mathrm{C}\right), 12 / 12$ light dark cycle (lights on/off at 0730/1930) and ad-lib food and water. All experiments were performed during the light phase of the light/dark cycle. All experimental procedures followed NIH guidelines and were approved by the University of Minnesota Institutional Animal Care and Use Committee (Protocol \# 0610A94146).

\section{Drugs}

\section{Lithium}

(SIGMA, St. Lewis, MI) was dissolved in saline and administered intraperitoenally (IP) at a $100 \mathrm{mg} / \mathrm{kg}$ or $200 \mathrm{mg} / \mathrm{kg}$ dose once or twice a day (see specific doses and regimens for experiments below) and at $10 \mathrm{ml} / \mathrm{kg}$ volume. When lithium was administered twice a day, injections were spaced approximately 12 hours apart. Administration of lithium started one week prior to the pre-conditioning test (see below) and continued throughout the conditioning period, post-conditioning test and post-CPP activity test. For the tests and conditioning days, lithium was administered 30 minutes prior to the CPP box exposure. Saline injections were used for control.

\section{d-Amphetamine}

(SIGMA, St. Lewis, MI) was dissolved in saline and administered at a $1 \mathrm{mg} / \mathrm{kg}$ dose and $10 \mathrm{ml} / \mathrm{kg}$ volume. Amphetamine (or saline control) was administered during the conditioning phase (as described below), immediately prior to placement of mice in the CPP apparatus.

All drug doses were based on previously demonstrated effects in other tests. The amphetamine dose was selected based on the effects to induce locomotor hyperactivity [10, $11,31,32]$ and the lithium doses based on their effects to attenuate manic-like behaviors in relevant tests, especially with emphasis on the amphetamine-hyperactivity test [11-13, $31,33]$.

\section{Apparatus \\ Conditioned Place Preference}

The CPP apparatus consisted of a wooden box, $60 \times 40 \times$ $45 \mathrm{~cm}$, divided by a partition to $1 / 3$ covered, black painted segment and $2 / 3$ open, well lit, white-painted segment. A digital camera interfaced with a computer was placed above the box and test sessions were digitally recorded for later analyses.

\section{Locomotor Activity}

locomotor activity was tested in $50 \times 25 \times 20 \mathrm{~cm}$ transparent plastic automated activity monitors (Opto3, Columbus Instruments, Columbus, OH, USA).

\section{Procedure}

\section{General}

For all experiments, mice were randomly assigned to mood stabilizer treatment or vehicle control group. Number of animals per group was 12-17 depends on specific experiment and group (see figure legends for details). Experiment 1 included 2 groups, lithium $100 \mathrm{mg} / \mathrm{kg}$ once daily and control. Experiment 2 included 3 groups, lithium $100 \mathrm{mg} / \mathrm{kg}$ once daily, lithium $100 \mathrm{mg} / \mathrm{kg}$ twice daily and control. Experiment 3 included 4 groups with lithium administration $(200 \mathrm{mg} / \mathrm{kg}$ twice daily) as one factor and amphetamine conditioning as a second factor. One week after the beginning of treatment with mood stabilizer, mice were subjected to the 10 days CPP procedure as described below. For Experiment 3, one day after the end of the CPP procedure animals were tested for activity levels. The general timeline of the experiments is described in Table $\mathbf{1 .}$

\section{Conditioned Place Preference}

Conditioned place preference (CPP) is a commonly used method to evaluate preferences for environmental stimuli associated with a reward $(19,20)$. For the present experiments we used a biased CPP protocol (e.g. [34]) with a box with one black and dark compartment and one white and well lit compartment. The CPP procedure consisted of 3 phases: (1) pre-conditioning test, (2) conditioning days and 
Table 1. General Timeline of Treatments and Tests for All Experiments

\begin{tabular}{|l|l|l|l|l|l|l|l|l|l|l|l|l|l|l|l|l|l|l|}
\hline Day & $\mathbf{1}$ & $\mathbf{2}$ & $\mathbf{3}$ & $\mathbf{4}$ & $\mathbf{5}$ & $\mathbf{6}$ & $\mathbf{7}$ & $\mathbf{8}$ & $\mathbf{9}$ & $\mathbf{1 0}$ & $\mathbf{1 1}$ & $\mathbf{1 2}$ & $\mathbf{1 3}$ & $\mathbf{1 4}$ & $\mathbf{1 5}$ & $\mathbf{1 6}$ & $\mathbf{1 7}$ & $\mathbf{1 8}$ \\
\hline \hline Treatment & \multicolumn{10}{|l|}{ Mood stabilizer } & \multicolumn{10}{l|}{ Mood stabilizer + amphetamine } & & Mood stabilizer \\
\hline Test & \multicolumn{10}{l|l}{$\begin{array}{l}\text { CPP } \\
\text { pre-test }\end{array}$} & CPP Conditioning & $\begin{array}{l}\text { CPP post- } \\
\text { test }\end{array}$ & $\begin{array}{l}\text { Locomotor activity } \\
\text { (Experiment 3) }\end{array}$ \\
\hline
\end{tabular}

(3) post-conditioning tests. Pre-conditioning test: Mice, naïve to the apparatus, were injected with saline and individually placed in the box with the partition between compartments slightly ajar to allow free transitions. All mice were placed in the white compartment of the apparatus. Behavior was recorded for a 10 minute session. At the end of the session, mice were removed from the box and re-placed in their home cages. Boxes were cleaned with $10 \%$ alcohol solution between mice. Conditioning phase: For experiments 1 and 2 all mice were conditioned with amphetamine. For Experiment 3, mice were randomly assigned to one of four groups according to a two factor design with amphetamine conditioning and lithium treatment as grouping factors. Experiment 3 therefore included 4 groups: (1) control-saline; (2) control-lithium; (3) amphetamine-saline and (4) amphetamine-lithium. For amphetamine conditioning (all experiments), placement into the white, lit compartment was paired with an amphetamine injection and placement into the black compartment was paired with a saline injection. For the control groups (Experiment 3) placement into both compartments was paired with saline injections. All mice received eight exposure sessions. On alternate days and immediately after the administration of amphetamine or saline, mice were placed in either the black (dark) compartment or the white (lit) compartment for a 30 minute session with the partition door closed. In this paradigm the amphetamine-paired groups received 4 pairings of amphetamine injections with the white (lit) compartment and 4 pairings of saline injection with the black (dark) compartment. Control animals (Experiment 3) received 4 pairings of saline injection with each compartments. Order of treatments and exposure to the different compartments was balanced. At the end of each session mice were removed from the box and re-placed in their home cages. Boxes were cleaned with $10 \%$ alcohol solution between mice. Postconditioning test: The post-conditioning test replicates the pre-conditioning test as described above. Mice were injected with saline and placed in the box with the partition door open for a 10 minute session that was digitally recorded for later analyses.

\section{Locomotor Activity}

Infrared beam crossings were recorded for $60 \mathrm{~min}$ in 10minutes intervals and total ambulatory activity was calculated across the entire session. At the end of the session mice were returned to their home cages and the boxes were wiped clean with a $10 \%$ alcohol solution. For technical reasons only some of the mice from each group were tested for locomotor activity. These mice were randomly selected and the number of mice per group in this test was 7-9 (see Table 2 for specific N's).

\section{Specific Experiments}

The study included 3 separate experiments. Experiment 1 tested the effects of $100 \mathrm{mg} / \mathrm{kg}$ lithium administered once daily. Experiment 2 tested the effects of $100 \mathrm{mg} / \mathrm{kg}$ lithium administered once or twice daily. Experiment 3 tested the effects of $200 \mathrm{mg} / \mathrm{kg}$ lithium administered twice daily. Experiment 3 also included control groups for amphetamineinduced CPP therefore permitting dissection of lithium's effects on conditioned versus unconditioned animals. Whereas the general design and timeline of all experiments were similar, Experiments 1 and 2 did not include nonamphetamine-treated groups (as mentioned above) and did not include a post-CPP test for locomotor activity.

\section{Analysis and Statistical Methods}

\section{Conditioned Place Preference}

Digital recordings of test sessions were manually scored for time spent in the white (lit) compartment of the CPP box. Data for experiments 1 and 2 [lithium $100 \mathrm{mg} / \mathrm{kg}$ once daily (Experiment 1) or once or twice daily (Experiment 2)] were analyzed with a repeated measures ANOVA with Treatment as a main factor and Test (pre-conditioning and postconditioning) as a repeated measure factor. For experiment 3 , the change in time in the white compartment from preconditioning to post-conditioning tests served as main

Table 2. Post-CPP Locomotor Activity

\begin{tabular}{|l|l|l|l|}
\hline Pairing History & Mood Stabilizer & $\begin{array}{l}\text { Locomotion (Beam Breaks } \\
\text { in } 60 \text { min) }\end{array}$ & Statistics (ANOVA) \\
\hline \hline \multirow{2}{*}{ Amph } & $\begin{array}{l}\text { Lithium } 200 \mathrm{mg} / \mathrm{kg} \\
\text { Vehicle }\end{array}$ & $\begin{array}{l}4388 \pm 611(\mathrm{~N}=9) \\
4468 \pm 736(\mathrm{~N}=8)\end{array}$ & $\begin{array}{l}\text { Amph history: } \mathrm{F}(1,28)=4.56, \mathrm{p}=0.042 \\
\text { Lithium: } \mathrm{F}(1,28)=0.58, \mathrm{~N} . \mathrm{S} . \\
\text { Amph history x Lithium Interaction: } \mathrm{F}(1,28)=0.8, \mathrm{~N} . \mathrm{S} .\end{array}$ \\
\cline { 1 - 3 } Saline & $\begin{array}{l}\text { Lithium } 200 \mathrm{mg} / \mathrm{kg} \\
\text { Vehicle }\end{array}$ & $\begin{array}{l}3664 \pm 355(\mathrm{~N}=7) \\
2694 \pm 491(\mathrm{~N}=8)\end{array}$ & \\
\hline
\end{tabular}

Amphetamine was not administered during the locomotor activity test day and the reference in column 1 is to the history of treatment during the CPP conditioning days. $\mathrm{Amph}=$ amphetamine $1 \mathrm{mg} / \mathrm{kg}$. 
measure and data were analyzed with a 2 way ANOVA with Lithium and Amphetamine as main factors.

Locomotor activity: (Experiment 3) data were analyzed using a two way ANOVA with Lithium treatment and Amphetamine history as main factors. Statistical significance for all experiments was set at $\mathrm{p}<0.05$.

\section{RESULTS}

\section{Experiment 1: Lithium 100mg/kg, Once Daily}

The pairing of amphetamine with the white compartment of the CPP box resulted in conditioned place preference but the administration of lithium once daily at $100 \mathrm{mg} / \mathrm{kg}$ had no effects on the expression of the amphetamine-induced CPP (Fig. 1; ANOVA: Conditioning effect $-\mathrm{F}(1,27)=16.81$, $\mathrm{p}<0.00)$; Lithium treatment effect $-\mathrm{F}(1,27)=0.3$, N.S; Conditioning $x$ Lithium Interaction $-F(1,27)=1.01$, N.S.(not significant)].

\section{Experiment 2: Lithium 100mg/kg, Once or Twice Daily}

Similar to Experiment 1, the pairing of amphetamine with the white compartment of the CPP apparatus resulted in increased time spent in that area from pre-conditioning to post-conditioning tests but the administration of lithium at a dose of $100 \mathrm{mg} / \mathrm{kg}$, once or twice daily, had no effects on CPP induced by amphetamine (Fig. 2; ANOVA: Conditioning effect $-\mathrm{F}(1,33)=80.78, \mathrm{p}<0.001$; Lithium treatment effect $-\mathrm{F}(2,33)=1.92$, N.S; Conditioning $\mathrm{x}$ Lithium Interaction $-\mathrm{F}(2,33)=1.37$, N.S.).

\section{Experiment 3: Lithium 200mg/kg Twice Daily}

As in the previous experiments, amphetamine pairing resulted in an increase of the time spent in the white compartment from pre-conditioning to post-conditioning tests and this effect was not observed in animals that experience pairing with saline. The administration of lithium at $200 \mathrm{mg} / \mathrm{kg}$ dose, twice daily had no effects on the amphetamine-induced CPP (Fig. 3; ANOVA: Amphetamine effect $-\mathrm{F}(1,52)=20.58, \quad \mathrm{p}<0.001$; Lithium effect $\mathrm{F}(1,52)=0.07$, N.S.; Amphetamine $\mathrm{x}$ Lithium Interaction $\mathrm{F}(1,52)=2.4$, N.S.). History of amphetamine treatment resulted in increased locomotor activity but lithium treatment had no effects on locomotion levels (see Table $\mathbf{2}$ for data and statistics). Although animals were not administered amphetamine during the locomotor activity test the increased activity levels of animals previously exposed to the drug is not surprising and might be related to a process of sensitization to psychostimulants (e.g. [35]).

\section{DISCUSSION}

The restricted availability of appropriate models for bipolar disorder is repeatedly cited as a significant factor limiting the ability to explore the complex biology of the disease and develop more efficacious treatments [3, 36, 37]. In an attempt to develop a battery of tests for domains of BPD, we have previously demonstrated that when utilizing an appropriate mouse strain, it is possible to model a number of behavioral facets that are directly linked to BPD. Specifically, we have shown that increased aggression and intrusion can be tested in the resident-intruder test [6], increased vigor and goal directed activity can be tested in the forced swim test [13] and that increased reward seeking behavior can be tested using the sweet solution preference test [12]. This is of course on top of the frequently used amphetamine-induced hyperactivity test [11]. Additional tests were suggested for more behavioral domains of the disorder but were not tested or validated yet $[6,8]$.

The sweet solution preference test can be a good way to evaluate the increased reward seeking behavior associated with mania [12] but is limited to strains and species with a clear preference for sweet taste. For example, a study that included an attempt to utilize the test (as part of a set of

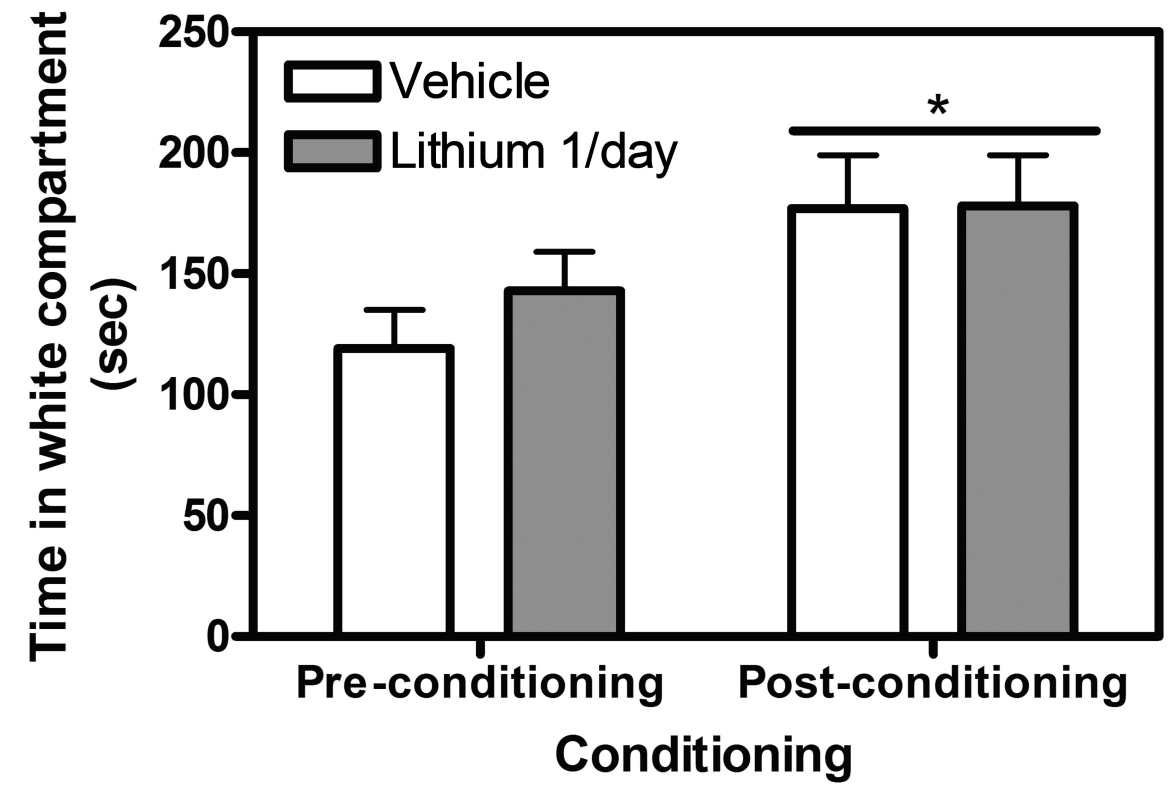

Fig. (1). The pairing of amphetamine with the white compartment resulted in a significant increase in time spent in that compartment from pre-conditioning to post-conditioning tests. The administration of $100 \mathrm{mg} / \mathrm{kg}$ lithium, once daily, during the conditioning period and tests had no effects on the amphetamine-induced CPP. Bars represent time (sec) spent in the white compartment during pre-conditioning and postconditioning tests of mice that experienced amphetamine pairing with this compartment. Open bars represent no mood stabilizer treatment $(\mathrm{N}=14)$, grey bars represent once daily administration of lithium $(\mathrm{N}=15)$. * symbolizes significant difference $(\mathrm{p}<0.05)$. 


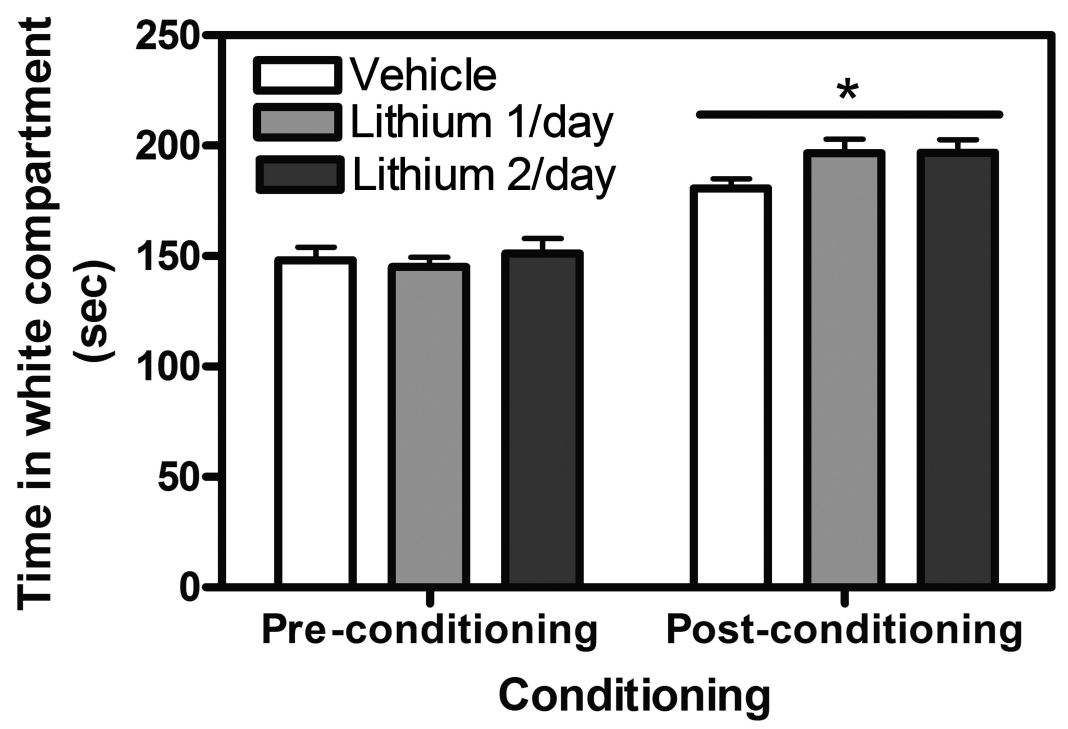

Fig. (2). The pairing of amphetamine with the white compartment resulted in a significant increase in time spent in that compartment from pre-conditioning to post-conditioning tests. The administration of $100 \mathrm{mg} / \mathrm{kg}$ lithium, once or twice daily, during the conditioning period and tests had no effects on the amphetamine-induced CPP. Bars represent time (sec) spent in the white compartment during pre-conditioning and post-conditioning tests of mice that experienced amphetamine pairing with this compartment. Open bars represent no mood stabilizer treatment $(\mathrm{N}=12)$, light grey bars represent once daily administration of lithium $(\mathrm{N}=12)$ and dark grey bars represent twice daily administration of lithium $(\mathrm{N}=12)$. ${ }^{*}$ symbolizes significant difference $(\mathrm{p}<0.05)$.

tests) in the context of affective disorders in the diurnal fat sand rats (Psammomys obesus) demonstrated no preference for sweet solution in this species [38] and suggested that sand rats do not develop preference for sweet solution because sugars are not part of their natural diet and that sand rats can develop nutritionally induced diabetes when exposed to sugars [39]. Hence, the present study was designed to evaluate the possibility of using the conditioned place preference paradigm as a way to model reward seeking behavior which is a critical behavioral domain, and possibly an endophenotype of mania [18, 40]. Amphetamine-induced CPP might have special relevance to mania because of the multiple lines of evidence suggesting involvement of amphetamine and dopaminergic agents in general in the pathophysiology of the disease.

One necessary step to evaluate the relevance of a model for a disorder is to examine its pharmacological validity (a component of predictive validity) and test if drugs that are efficacious in treating the disorder also have a beneficial behavioral effect in the model $[36,41,42]$. To that end the present study evaluated the effects of the prototypic mood stabilizer lithium in amphetamine-induced CPP.

The results of the study do not offer support for the validity of the paradigm to model the reward seeking domain of mania. Administration of lithium at doses and regimens that were previously demonstrated to ameliorate amphetamine-induced hyperactivity $[10,11,31,33]$ and reduce sweet solution preference $[11,12]$ had no effects on amphetamine-induced CPP.

The present study did not specifically attempt to distinguish between development and expression of CPP. To do that, experiments should be designed to test the effects of lithium administration throughout the conditioning phase but not during the post-conditioning test (development) compared with administration of lithium just before the post- conditioning test (expression). Instead, we used a chronic lithium administration regimen that started before the CPP paradigm and continued throughout all phases of conditioning and testing. This administration regimen was selected as it covers both CPP acquisition and expression and could demonstrate potential lithium effects on both processes. Positive results from this broader administration regimen could have been followed later by separate experiments to distinguish development and expression of CPP. However, the lack of effects in the present study suggests that lithium does not influence either the development or expression of amphetamine-induced CPP.

The lack of effects of lithium in amphetamine-induced CPP appears to be in some contrast to its repeatedly demonstrated effects in the amphetamine-induced hyperactivity model including work with the same mouse strain and similar doses used in the present study [10, 11, 31, 33]. However, the systems related to the inhibition of amphetamine-induced hyperactivity and amphetamineinduced reward seeking might be different. For example, blocking amphetamine hyperactivity had been related to areas of the frontal cortex $[43,44]$ whereas midbrain areas and connections had been implicated in amphetamine rewarding effects [45]. Such brain-region specific effects were also recently demonstrated in the context of mitochondrial dysfunction, amphetamine and lithium [46]. In that study, while lithium treatment normalized amphetamineinduced hyperactivity, its effects on amphetamine-induced mitochondrial dysfunction were restricted to the prefrontal cortex and the striatum but it had no effect on the hippocampus [46]. The different systems involved with the different actions of amphetamine and the different interactions of lithium with these systems can therefore explain the discrepancy between lithium's effects in amphetamine-induced hyperactivity and the lack of effects in amphetamine-induced CPP. 


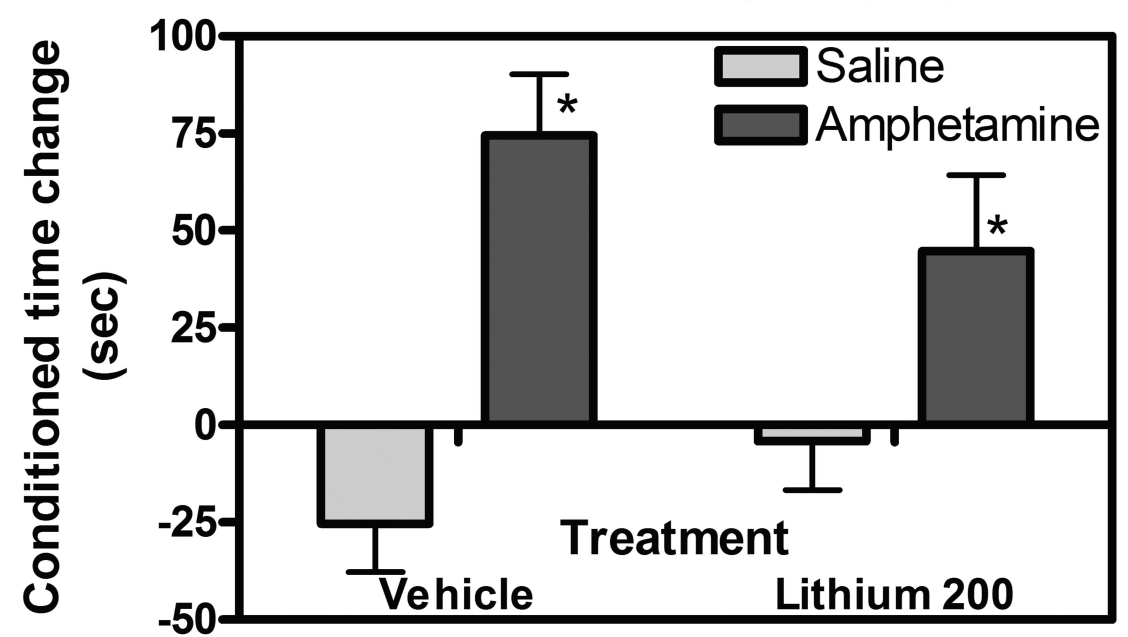

Fig. (3). The pairing of amphetamine with the white compartment resulted in a significant increase in time spent in that compartment from pre-conditioning to post-conditioning tests. The administration of $200 \mathrm{mg} / \mathrm{kg}$ lithium, twice daily, during the conditioning period and tests had no effects on the amphetamine-induced CPP. Bars represent change in time (sec) spent in the white compartment from the pre-conditioning to the post-conditioning test. Light bars represent animals without amphetamine pairing and dark bars animals that experienced amphetamine pairing. $\mathrm{N}=12$ /group for vehicle groups, $\mathrm{N}=15$ for Lithium/Saline group and $\mathrm{N}=17$ for Lithium/Amphetamine group. * symbolizes significant difference between amphetamine-paired and unpaired groups $(\mathrm{p}<0.05)$.

\section{CONCLUSIONS}

The present study does not support the pharmacological validity of the amphetamine-induced CPP paradigm to model reward seeking behavior in the context of BPD. It is however possible that other drugs utilized in the treatment of BPD such as different mood stabilizers or atypical antipsychotics will be effective and experiments are planned to evaluate valproate and risperidone in the paradigm. Previous work already demonstrated that when using a battery of models behavioral tests 250 , these drugs are not identical in their effects and some might be more efficacious than others for testing specific domains of the disorder [11, 47]. In parallel with evaluating additional drugs, additional methods should be explored to enhance the battery of models for domains of BPD as a way to augment our ability to study the underlying biology of the disorder and screen for novel treatments.

\section{ACKNOWLEDGEMENTS}

Study was supported by a NARSAD Independent Investigator Award to HE. The authors would like to thank H. Gagne for her technical assistance.

\section{REFERENCES}

[1] Sadock JB, Sadock VA. Kaplan and Sadock's Synopsis of Psychiatry. 10 ed. Philadelphia: Lippincott \& Williams 2007.

[2] Tecott LH, Nestler EJ. Neurobehavioral assessment in the information age. Nat Neurosci 2004; 7: 462-6.

[3] Gould TD, Einat H. Animal models of bipolar disorder and mood stabilizer efficacy: a critical need for improvement. Neurosci Biobehav Rev 2007; 31: 825-31.

[4] Gessa GL, Pani L, Serra G, Fratta W. Animal models of mania. Adv Biochem Psychopharmacol 1995; 49: 43-66.

[5] Malatynska E, Knapp RJ. Dominant-submissive behavior as models of mania and depression. Neurosci Biobehav Rev 2005; 29: 715-37.

[6] Einat H. Establishment of a battery of simple models for facets of bipolar disorder: a practical approach to achieve increased validity, better screening and possible insights into endophenotypes of disease. Behav Genet 2007; 37: 244-55.

[7] Einat H. Modelling facets of mania-new directions related to the notion of endophenotypes. J Psychopharmacol 2006; 20: 714-22.
[8] Einat H. Different behaviors and different strains: potential new ways to model bipolar disorder. Neurosci Biobehav Rev 2007; 31 : 850-7.

[9] Einat H, Shaldubina A, Bersudskey Y, Belmaker RH. In: Soares JC, Young A, Eds. Bipolar disorders: basic mechanisms and therapeutic implications. 2nd ed. New York: Taylor \& Francis 2007.

[10] Hiscock KM, Linde JA, Einat H. Black Swiss mice as a new animal model for mania: a preliminary study. J Med Biol Sci 2007; 1: 1-7.

[11] Flaisher-Grinberg S, Einat H. Strain Specific battery of tests for separate behavioral domains of mania. Front Psychiatry 2010;1:110 .

[12] Flaisher-Grinberg S, Overgaard S, Einat H. Attenuation of high sweet solution preference by mood stabilizers: a possible mouse model for the increased reward-seeking domain of mania. J Neurosci Methods 2009; 177: 44-50.

[13] Flaisher-Grinberg S, Einat H. A possible utilization of the mice forced swim test for modeling manic-like increase in vigor and goal-directed behavior. J Pharmacol Toxicol Methods 2009; 59: 141-5.

[14] Malkesman O, Scattoni ML, Paredes D, et al. The female urine sniffing test: a novel approach for assessing reward-seeking behavior in rodents. Biol Psychiatry 2009; 67: 864-71.

[15] Johnson SL. Mania and dysregulation in goal pursuit: a review. Clin Psychol Rev 2005; 25: 241-62.

[16] Abler B, Greenhouse I, Ongur D, Walter H, Heckers S. Abnormal reward system activation in mania. Neuropsychopharmacology 2007; 7: 7 .

[17] Abler B, Erk S, Walter H. Human reward system activation is modulated by a single dose of olanzapine in healthy subjects in an event-related, double-blind, placebo-controlled fMRI study. Psychopharmacology (Berl) 2007; 191: 823-33.

[18] Hasler G, Drevets WC, Gould TD, Gottesman II, Manji HK. Toward constructing an endophenotype strategy for bipolar disorders. Biol Psychiatry 2006; 60: 93-105.

[19] Schechter MD, Calcagnetti DJ. Trends in place preference conditioning with a cross-indexed bibliography; 1957-1991. Neurosci Biobehav Rev 1993; 17: 21-41.

[20] Bardo MT, Bevins RA. Conditioned place preference: what does it add to our preclinical understanding of drug reward? Psychopharmacology (Berl) 2000; 153: 31-43.

[21] Spyraki C, Fibiger HC, Phillips AG. Dopaminergic substrates of amphetamine-induced place preference conditioning. Brain Res 1982; 253: 185-93.

[22] Adriani W, Laviola G. Spontaneous novelty seeking and amphetamine-induced conditioning and sensitization in adult mice: 
evidence of dissociation as a function of age at weaning. Neuropsychopharmacology 2002; 27: 225-36.

[23] Bowling SL, Bardo MT. Locomotor and rewarding effects of amphetamine in enriched, social, and isolate reared rats. Pharmacol Biochem Behav 1994; 48: 459-64.

[24] Anand A, Verhoeff P, Seneca N, et al. Brain SPECT imaging of amphetamine-induced dopamine release in euthymic bipolar disorder patients. Am J Psychiatry 2000; 157: 1108-14.

[25] Huey LY, Janowsky DS, Judd LL, Abrams A, Parker D, Clopton P. Effects of lithium carbonate on methylphenidate-induced mood, behavior, and cognitive processes. Psychopharmacology (Berl) 1981; 73: 161-4.

[26] Van Kammen DP, Murphy DL. Attenuation of the euphoriant and activating effects of $\mathrm{d}$ - and 1-amphetamine by lithium carbonate treatment. Psychopharmacologia 1975; 44: 215-24.

[27] You ZD, Li JH, Song CY, Lu CL, He C. Oxytocin mediates the inhibitory action of acute lithium on the morphine dependence in rats. Neurosci Res 2001; 41: 143-50.

[28] Mu P, Yu LC. Valproic acid sodium inhibits the morphine-induced conditioned place preference in the central nervous system of rats. Neurosci Lett 2007; 426: 135-8.

[29] Spyraki C, Kazandjian A, Varonos D. Diazepam-induced place preference conditioning: appetitive and antiaversive properties. Psychopharmacology (Berl) 1985; 87: 225-32.

[30] Shippenberg TS, Heidbreder C. The delta-opioid receptor antagonist naltrindole prevents sensitization to the conditioned rewarding effects of cocaine. Eur J Pharmacol 1995; 280: 55-61.

[31] Gould TD, O'Donnell KC, Picchini AM, Manji HK. Strain differences in lithium attenuation of d-amphetamine-induced hyperlocomotion: a mouse model for the genetics of clinical response to lithium. Neuropsychopharmacology 2007; 32: 1321-33.

[32] Wang J, Flaisher-Grinberg S, Li S, et al. Antidepressant-like effects of the active acidic polysaccharide portion of ginseng in mice. J Ethnopharmacol 2010; 132: 65-9.

[33] Kalinichev M, Dawson LA. Evidence for antimanic efficacy of glycogen synthase kinase-3 (GSK-3) inhibitors in a strain specific model of acute mania. Int J Neuropsychopharmacol 2011; 6: 1-17.

[34] Papp M, Gruca P, Willner P. Selective blockade of drug-induced place preference conditioning by ACPC, a functional NDMAreceptor antagonist. Neuropsychopharmacology 2002; 27(5): 72743.
[35] Einat H, Szechtman H. Longlasting consequences of chronic treatment with the dopamine agonist quinpirole for the undrugged behavior of rats. Behav Brain Res 1993; 54: 35-41.

[36] Cryan JF, Slattery DA. Animal models of mood disorders: Recent developments. Curr Opin Psychiatry 2007; 20: 1-7.

[37] Machado-Vieira R, Kapczinski F, Soares JC. Perspectives for the development of animal models of bipolar disorder. Prog Neuropsychopharmacol Biol Psychiatry 2004; 28: 209-24.

[38] Krivisky K, Ashkenazy T, Kronfeld-Schor N, Einat H. Antidepressants reverse short-photoperiod-induced, forced swim test depression-like behavior in the diurnal fat sand rat: further support for the utilization of diurnal rodents for modeling affective disorders. Neuropsychobiology 2011; 63: 191-6.

[39] Shafrir E, Gutman A. Psammomys obesus of the Jerusalem colony: a model for nutritionally induced, non-insulin-dependent diabetes. J Basic Clin Physiol Pharmacol 1993; 4: 83-99.

[40] Benjamin J, Ebstein RP, Lesch KP. Genes for personality traits: implications for psychopathology. Int $\mathrm{J}$ Neuropsychopharmacol 1998; 1: 153-168.

[41] Willner P. In: Willner P, Ed. Behavioral models in psychopharmacology: theoretical, industrial and clinical perspectives. Cambridge, Cambridge University Press 1991. pp. 319.

[42] Willner P. The validity of animal models of depression. Psychopharmacology (Berl) 1984; 83: 1-16.

[43] Parmentier-Batteur S, Obrien JA, Doran S, et al. Differential effects of the mGluR5 positive allosteric modulator CDPPB in the cortex and striatum following repeated administration. Neuropharmacology 2010; 2010: 26.

[44] Bast T, Pezze MA, Feldon J. Dopamine receptor blockade in the rat medial prefrontal cortex reduces spontaneous and amphetamineinduced activity and does not affect prepulse inhibition. Behav Pharmacol 2002; 13: 669-73.

[45] Ikemoto S. Dopamine reward circuitry: two projection systems from the ventral midbrain to the nucleus accumbens-olfactory tubercle complex. Brain Res Rev 2007; 56: 27-78.

[46] Valvassori SS, Rezin GT, Ferreira CL, et al. Effects of mood stabilizers on mitochondrial respiratory chain activity in brain of rats treated with d-amphetamine. J Psychiatr Res 2010; 44: 903-9

[47] Hannah-Poquette C, Anderson GW, Flaisher-Grinberg S, Wang J, Meinerding TM, Einat H. Modeling mania: further validation for Black Swiss as model animals. Behav Brain Res 2011: 223: 222-6.

This is an open access article licensed under the terms of the Creative Commons Attribution Non-Commercial License (http://creativecommons.org/licenses/by-nc/3.0/) which permits unrestricted, non-commercial use, distribution and reproduction in any medium, provided the work is properly cited. 